\title{
Distribution of phytochemicals in stems and leaves of Cichorium intybus and Matricaria chamomilla: assessment of their antioxidant and antimicrobial potential
}

\author{
Tasaduq Peerzada, Jeena Gupta* \\ School of Bioengineering and Biosciences, Lovely Professional University (LPU), Phagwara, Punjab (India)
}

\begin{abstract}
Cichorium intybus (Chicory) and Matricaria chamomilla (Chamomile) are well-known medicinal herbs. On the basis of their medicinal values, we analyzed the distribution of phytochemicals in their stems and leaves, including their antioxidant and antimicrobial potential. The phytochemicals were analyzed using standard biochemical tests. The antioxidant potential, total phenolic content (TPC) and total flavonoids were determined by DPPH free radical scavenging activity, Folin-Ciocalteu method and aluminum chloride colorimetric assays, respectively. The antimicrobial activity of extracts was analyzed against 4 pathogenic bacteria; namely, Escherichia coli, Staphylococcus aureus, Pseudomonas aeruginosa and Bacillus subtilis. Aqueous extracts of Chicory stems and leaves exhibited better DPPH free radical scavenging activity (50\% DPPH inhibition at $6.01 \pm 0.28 \mu \mathrm{g} / \mathrm{ml}$ ) than aqueous extracts of Chamomile ( $50 \%$ inhibition at $18.90 \pm 0.37 \mu \mathrm{g} / \mathrm{ml}$ ). This corresponded to higher flavonoid and phenol concentrations in Chicory stems $(17.24 \pm 0.48 \mu \mathrm{g} / \mathrm{ml}$ and $19.77 \pm 0.20 \mu \mathrm{g} / \mathrm{ml}$, respectively) and leaves (18.36 $\pm 0.32 \mu \mathrm{g} / \mathrm{ml}$ and $10.8 \pm 0.12 \mu \mathrm{g} / \mathrm{ml}$, respectively) than in Chamomile $(11.5 \pm 0.56 \mu \mathrm{g} / \mathrm{ml}$ total flavonoid concentration and $19.28 \pm 0.87 \mu \mathrm{g} / \mathrm{ml}$ total phenol concentration in leaves and $7.76 \pm 0.32 \mu \mathrm{g} / \mathrm{ml}$ and $10.47 \pm 0.46 \mu \mathrm{g} / \mathrm{ml}$ in stem, respectively). The maximum antimicrobial activity against all 4 bacterial strains was observed in leaf and stem extracts of $C$. intybus, as compared to $M$. chamomilla. Our results confirmed that there is a specific distribution of phytochemicals in stems and leaves of both Chicory and Chamomile. Moreover, both these plants are potential sources of natural antioxidants and antimicrobials and thus can be used for medicinal and pharmaceutical purposes.
\end{abstract}

Key words: Chicory, Chamomile, phytochemicals, antioxidants, antimicrobials

\section{Introduction}

Phytochemicals are a diverse group of molecules widely distributed in plants (Saxena et al., 2013). These chemicals have gained attention since prehistoric times owing to their multitude of effects on human health and human physiology and their economic importance. Basically, secondary metabolites can be classified into 3 broad classes: alkaloids, phenolics, and terpenoids (Kennedy and Whitman, 2011). The molecules belonging to these groups further possess several types of modifications, thus increasing the diversity of secondary metabolites. Considering this, it is no surprise that significant attention is focused on the identification of plants rich in putative phytochemicals and their characterization in terms of their medicinal and economic value. In this regard, Cichorium intybus (Chicory) and Matricaria chamomilla are of great importance due to the documented presence of several important phytochemicals.

Cichorium intybus and Matricaria chamomilla are members of the Asteraceae family which is widely distributed in Asia. These plants have been recognized for their medicinal importance owing to the presence of a diverse variety of phytochemicals, such as alkaloids, flavonoids, terpenes, saponins, and tannins (Molan et al., 2003; Srivastava et al., 2010). Many Chicory varieties are relatively important as agricultural crops with great

\footnotetext{
* Corresponding author: Department of Biochemistry, School of Bioengineering and Biosciences, Lovely Professional University (LPU), Jalandhar - Delhi G.T. Road, Phagwara, Punjab (India) - 144411; e-mail: jeena.20104@1pu.co.in
} 
commercial values (Piluzza et al., 2014). Chicory is mostly consumed in raw salads in winter when many fresh vegetables are not available, as it is particularly resistant to low temperatures (Rosetto et al., 2005). Leaves of Chicory are good sources of phenols, vitamins, and minerals such as calcium, phosphorus, and potassium (Mulabagal et al., 2009). Furthermore, Chicory is rich in cichoric acid that stimulates the human immune system and thus prevents inflammation and bacterial infections (Ahmed et al., 2009). Cichorium intybus has been traditionally used for the treatment of fever, diarrhea, jaundice, and gallstones (Afzal et al., 2009). It has also been reported that $C$. intybus has antibacterial (Nandagopal and Rajitha Kumari, 2007), anti-inflammatory (Cavin et al., 2005), anti-hyperglycemic (Jackson et al., 2017) and anti-ulcerogenic activities (Rifat-uz-Zaman et al., 2006). The antioxidants present in Chicory may prevent oxidative damage to macromolecules such as lipids, proteins, and nucleic acids by scavenging various free radicals produced in the body during many biochemical processes (Shui and Leong, 2004). Free radicals which are produced due to oxidative stress react with lipids, proteins, and nucleic acids and induce apoptosis, which may lead to various neurological, cardiovascular and other physiological disorders (Uttara et al., 2009). Flavonoids, phenolic acids, ascorbic acid and tocopherols are well-known subclasses of phytochemical compounds which possess antioxidant properties and are used for the treatment of free radicle induced ailments (Bergman et al., 2001).

Matricaria chamomilla, also known as Chamomile, is a well-known medicinal plant from the Asteraceae family. Similar to Chicory, Chamomile is well-known for its medicinal value and has been used as an anti-inflammatory, antiseptic, antispasmodic and mildly sudorific compound (Mericili, et al., 1990). The international demand for Chamomile oil has been increasing steadily as the oil possesses antibacterial and antifungal properties (Singh et al., 2011). It also improves digestion and is used as a mild sedative (Gould et al., 1973). Chamomile is also known to possess anticancer activity. A mechanism of action via inducing necrosis / apoptosis, decreasing cell migration and invasion of cancerous cells in human breast cancer cell lines has recently been demonstrated (Nikseresht et al., 2017). Furthermore, it has been shown that Chamomile consumption significantly reduces the symptoms of generalized anxiety disorder (Mao et al., 2016).
Despite these observations, our knowledge pertaining to phytochemical profiles in different parts of the aforementioned plants is limited. There is a lack of comparative, qualitative and quantitative data regarding the distribution of various phytochemicals in $C$. intybus and $M$. chamomilla. Thus, the present study aimed at the identification of putative phytochemicals from stems and leaves of $C$. intybus and $M$. chamomilla, followed by their quantification, and assessment of antimicrobial and antioxidant activities of plant extracts.

\section{Materials and methods}

\section{Collection of plant material}

Chicory intybus and Matricaria chamomilla plants were randomly collected from Srinagar, Kashmir, India. The plant samples were thoroughly washed with tap water and then rinsed with distilled water. After this, the plants were dried in a hot air oven for $2-3 \mathrm{~h}$ at $40^{\circ} \mathrm{C}$. The leaves and the stems from both plants were separated and subsequently crushed to a fine powder with a pestle and mortar and stored in sealed polythene bags below $4{ }^{\circ} \mathrm{C}$ until further use.

\section{Preparation of aqueous extracts of stems and leaves}

Aqueous extracts of stems and leaves were prepared by dissolving $20 \mathrm{~g}$ of stem and leaf powders in $250 \mathrm{ml}$ of water. All mixtures were incubated in an orbital shaker for $72 \mathrm{~h}$ at $28^{\circ} \mathrm{C}$ with shaking $(60 \mathrm{rpm})$. The extracts were filtered through two folds of muslin cloth and the filtrates were collected in $250 \mathrm{ml}$ conical flasks. All filtrates were stored in a refrigerator at $4{ }^{\circ} \mathrm{C}$ until further use.

\section{Analyses of phytochemicals}

The aqueous extracts of stems and leaves were studied for the presence of various phytochemicals following protocols described by Arya and coworkers (2012).

\section{Test for alkaloids}

Mayer's reagent test: to $3 \mathrm{ml}$ of extracts, $1 \mathrm{ml}$ of $1 \% \mathrm{HCl}$ was added. The mixture was gently heated to $37^{\circ} \mathrm{C}$ for $20 \mathrm{~min}$. in a water bath, then allowed to cool, and filtered through a muslin cloth. After this, 2 drops of Mayer's reagent were mixed with $1 \mathrm{ml}$ of filtrate and the solution was observed for the presence of creamy precipitates. 


\section{Test for carbohydrates}

Molisch test: to $1 \mathrm{ml}$ of extract, 2-3 drops of Molisch's reagent were added (10\% of 1-naphthol in ethanol). The test tubes were kept at an angle and 1-2 $\mathrm{ml}$ of concentrated $\mathrm{H}_{2} \mathrm{SO}_{4}$ was carefully added along the sides of the test tubes. The extracts were observed for the formation of a reddish violet ring on the surface.

\section{Test for flavonoids}

$\mathrm{NaOH}$ test: three milliliters of extracts were treated with $1 \mathrm{ml}$ of $10 \%$ aqueous $\mathrm{NaOH}$ solution. The appearance of an intense yellow color of the mixture which turned colorless upon the addition of a few drops of diluted $\mathrm{HCl}$ indicated the presence of flavonoids.

$\mathrm{H}_{2} \mathrm{SO}_{4}$ test: a few drops of concentrated $\mathrm{H}_{2} \mathrm{SO}_{4}$ were added to $1 \mathrm{ml}$ of extracts along the sides of the test tubes. The appearance of a yellow color indicated the presence of flavonoids.

\section{Test for glycosides}

$\mathrm{FeCl}_{3}$ test: to $2.5 \mathrm{ml}$ of extracts, $5 \mathrm{ml}$ of concentrated $\mathrm{H}_{2} \mathrm{SO}_{4}$ was added and the mixture was boiled for $15 \mathrm{~min}$ in a water bath. The mixtures were cooled and neutralized with $20 \% \mathrm{KOH}$. Three drops of $\mathrm{FeCl}_{3}$ were added to half of the mixture and this was observed for the appearance of green-to-black precipitates.

\section{Test for gums and mucilage}

One milliliter of extract was mixed with $2.5 \mathrm{ml}$ of absolute alcohol under constant stirring. The formation of precipitates indicated the presence of gums and mucilage.

\section{Test for phenol}

$\mathrm{FeCl}_{3}$ test: a few drops of $10 \%$ aqueous $\mathrm{FeCl}_{3}$ were added to $2-3 \mathrm{ml}$ of extract and the mixture was observed for the emergence of a blue-green color.

\section{Test for phlobatannins}

A few drops of $2 \%$ aqueous $\mathrm{HCl}$ were added to $1 \mathrm{ml}$ of extract and the mixture was boiled for a few minutes. The appearance of red precipitates indicated the presence of phlobatannins.

\section{Test for reducing sugars}

Three milliliters of each Fehling solution A and B (Himedia) were mixed, then $1 \mathrm{ml}$ of extract was added and the mixture was boiled for 5-10 min. Brown-red precipitates indicated the presence of reducing sugars.

\section{Test for saponins}

Froth test: two milliners of extracts was shaken vigorously in test tubes, and observed for froth formation.

\section{Test for steroids}

Liebermann-Burchard test: one milliliter of extract was mixed with $1 \mathrm{ml}$ of chloroform. A volume of 2-3 $\mathrm{ml}$ of acetic anhydride was added to the mixture. Two drops of concentrated $\mathrm{H}_{2} \mathrm{SO}_{4}$ were added on the sides of the test tubes and observed for the appearance of a blue-green color

$\mathbf{H}_{2} \mathrm{SO}_{4}$ test: to $1 \mathrm{ml}$ of extract, 6-7 drops of concentrated $\mathrm{H}_{2} \mathrm{SO}_{4}$ were added on the walls of the test tubes. The appearance of a red color indicated the presence of steroids.

\section{Test for tannins}

$\mathrm{FeCl}_{3}$ test: as many as 1-2 drops of $\mathrm{FeCl}_{3}$ were added to $1 \mathrm{ml}$ of extract and this was observed for the appearance of a dark green color.

KOH test: one milliliter of freshly prepared 10\% $\mathrm{KOH}$ was added to $1 \mathrm{ml}$ of extract. The formation of dirty-white precipitates indicated the presence of tannins.

\section{Test for terpenoids}

Salkowaski test: one milliliter of extracts was mixed with $2 \mathrm{ml}$ of chloroform. Three milliliters of concentrated $\mathrm{H}_{2} \mathrm{SO}_{4}$ was added carefully on the walls of the test tubes. The appearance of a reddish-brown coloration at the interface indicated the presence of terpenoids.

\section{Antioxidant activity of Chicory and Chamomile aqueous extracts}

The Blois method (Blois, 1958) was used to determine the free radical scavenging activity of the plant extracts by using DPPH (2,2-diphenyl-1-picrylhydrazyl) as a free radical. Briefly, $0.2 \mathrm{mM} \mathrm{DPPH}$ solution was made by dissolution in methanol. Five different concentrations of ascorbic acid (used as a standard: $5 \mu \mathrm{g} / \mathrm{ml}, 10 \mu \mathrm{g} / \mathrm{ml}$, $15 \mu \mathrm{g} / \mathrm{ml}, 20 \mu \mathrm{g} / \mathrm{ml}, 25 \mu \mathrm{g} / \mathrm{ml}$ ) were used to make the standard curve. The test samples were made by taking $10 \mu \mathrm{l}$ of each extract and dissolving this in $2 \mathrm{ml}$ of methanol. One milliliter of DPPH solution was added to 
each tube. The tubes were kept in the dark for $60 \mathrm{~min}$ and the absorbance of all samples was measured at $517 \mathrm{~nm}$ using a spectrophotometer.

The percentage of inhibition was calculated using the following formula:

$$
\left[\left(A_{\text {control }}-A_{\text {extract }}\right) /\left(A_{\text {control }}\right)\right] \times 100
$$

where $A$ is the absorbance of control and extract, respectively.

\section{Total phenolic content in Chicory and Chamomile plant stem/leaf aqueous extracts}

To determine total phenolic content in plant extracts, gallic acid was used as a standard following the protocol given by Siddhuraju and colleagues (Siddhuraju et al., 2003). The stock solution of the gallic acid was made by dissolving $10 \mathrm{mg}$ gallic acid in $100 \mathrm{ml}$ of distilled water. Five different concentrations of the Gallic acid were used as standards $(2 \mu \mathrm{g} / \mathrm{ml}, 4 \mu \mathrm{g} / \mathrm{ml}, 6 \mu \mathrm{g} / \mathrm{ml}$, $8 \mu \mathrm{g} / \mathrm{ml}, 10 \mu \mathrm{g} / \mathrm{ml}$ ) and these were used to make a standard curve. A volume of $20 \mu \mathrm{l}$ of each extract was taken and adjusted to $2 \mathrm{ml}$ using distilled water. $200 \mu \mathrm{l}$ of Folin-Ciocalteu reagent and $500 \mu \mathrm{l}$ of $20 \% \mathrm{Na}_{2} \mathrm{CO}_{3}$ were added to each tube. The reaction mixtures were incubated for $1 \mathrm{~h}$ at room temperature and the absorbance was measured at $760 \mathrm{~nm}$ using a spectrophotometer.

\section{Quantification of the flavonoid contents in the plant aqueous extracts}

For the quantification of the flavonoid content, quercetin was used as a standard following the protocol given by Jia and colleagues (Zhishen et al., 1999). Different concentrations of quercetin ( $2 \mu \mathrm{g}, 4 \mu \mathrm{g}, 6 \mu \mathrm{g}, 8 \mu \mathrm{g}, 10 \mu \mathrm{g} / \mathrm{ml}$ ) were used to make a standard curve. For test samples, 10 $\mu \mathrm{l}$ of each extract were dissolved in $100 \mu \mathrm{l}$ of distilled water. The final volume of each sample was adjusted to $2 \mathrm{ml}$ by adding $1 \mathrm{ml}$ of $2 \%$ solution of aluminum chloride and distilled water. The samples were then incubated for $30 \mathrm{~min}$ at room temperature and the OD was measured at $470 \mathrm{~nm}$ using a spectrophotometer.

\section{Determination of the antimicrobial potential of Chicory and Chamomile aqueous extracts}

The antimicrobial potential of plant extracts was evaluated against 4 pathogenic strains of bacteria (namely, Escherichia coli, Bacillus subtilis, Staphylococcus aureus and Pseudomonas aeruginosa) by the disk diffusion method on nutrient agar media, using streptomycin sulfate as a positive control (Zaidan et al., 2005). The experiments were repeated 3 times. The bacterial cultures were spread on each plate using a sterile glass spreader. The sterile filter paper disks were placed on agar plates and to each disk $50 \mu \mathrm{l}$ of crude plant extract was carefully added under sterile conditions. The plates were incubated overnight at $37^{\circ} \mathrm{C}$ in an incubator and the presence of inhibition zones (mm) was analyzed the following day.

\section{Statistical analysis}

The extracts were made from 3 different plants and tests were performed for each plant separately. Experimental values are expressed as mean \pm SEM. Comparison of mean values between various groups was performed by one way-analysis of variance (one way-ANOVA). $P$-value $<0.05$ was considered to be significant.

\section{Results}

\section{Analyses of phytochemicals}

The stems and leaves of both plants were screened for the presence or absence of different phytochemicals. Flavonoids, phenols, saponins, steroids, tannins, glycosides, and terpenoids were present in both plant extracts, but the amounts differed. In the case of Chicory intybus, flavonoids, steroids, tannins, and terpenoids were abundantly present in leaves. Phenols were mildly present, and saponins were found in trace amounts. Similarly, in stem extracts flavonoids, phenols, saponins, and terpenoids were abundantly present, while steroids and tannins were found in lesser amounts (Table 1).

In the case of Matricaria chamomilla, the phenols, flavonoids, and glycosides were abundantly present in leaves, while in stem extracts flavonoids, phenols, and saponins were present in higher amounts. Similar to Chicory leaves, saponins and tannins were present in lesser amounts in Chamomile leaves. Alkaloids and gums and mucilage were absent from leaf extracts of Chamomile. Terpenoids were found in trace amounts in both stem and leaf extracts. Steroids were absent from stem extracts, while tannins were present in a small amount (Table 2).

\section{DPPH free radical scavenging activity}

DPPH free radical scavenging activity was analyzed for each plant extract. Eight different amounts (20 $-160 \mu \mathrm{l})$ were used to assess the antioxidant potentials 
Table 1. Results of analysis of phytochemical composition in stem and leaf aqueous extracts of Chicory intybus

\begin{tabular}{l|c|c}
\hline $\begin{array}{c}\text { Phytochemicals } \\
\text { Chicory intybus) }\end{array}$ & $\begin{array}{c}\text { Aqueous leaf } \\
\text { extract }\end{array}$ & $\begin{array}{c}\text { Aqueous stem } \\
\text { extract }\end{array}$ \\
\hline Alkaloids & - & - \\
\hline Carbohydrates & ++ & +++ \\
\hline Flavonoids & +++ & +++ \\
\hline Glycosides & + & ++ \\
\hline Gums and mucilage & - & - \\
\hline Phenolics & ++ & +++ \\
\hline Phlobatannins & ++ & ++ \\
\hline Reducing sugars & +++ & ++ \\
\hline Saponins & + - & +++ \\
\hline Steroids & +++ & ++ \\
\hline Tannins & ++ & ++ \\
\hline Terpenoids & ++ & +++ \\
\hline
\end{tabular}

Table 2. Analysis of phytochemical composition in stem and leaf aqueous extracts of Matricaria chamomilla

\begin{tabular}{l|c|c}
\hline $\begin{array}{c}\text { Phytochemicals } \\
\text { Matricaria chamomilla) }\end{array}$ & $\begin{array}{c}\text { Aqueous leaf } \\
\text { extract }\end{array}$ & $\begin{array}{c}\text { Aqueous stem } \\
\text { extract }\end{array}$ \\
\hline Alkaloids & - & + \\
\hline Carbohydrates & 0 & +++ \\
\hline Flavonoids & +++ & +++ \\
\hline Glycosides & - & ++ \\
\hline Gums and mucilage & +++ & - \\
\hline Phenolics & ++ & +++ \\
\hline Phlobatannins & +++ & ++ \\
\hline Reducing sugars & + & +++ \\
\hline Saponins & +++ & +++ \\
\hline Steroids & ++ & - \\
\hline Tannins & $+/-$ & ++ \\
\hline Terpenoids & & $+/-$ \\
\hline
\end{tabular}

of stem and leaf extracts of Cichorium intybus and Matricaria chamomilla. The aqueous extracts of Chicory stems and leaves exhibited maximum antioxidant activity with $50 \%$ inhibition $\left(\mathrm{IC}_{50}\right)$ at $6.01 \pm 0.28 \mu \mathrm{g} / \mathrm{ml}$ and 3.52 $\pm 0.35 \mu \mathrm{g} / \mathrm{ml}$, which was much better than the antioxidant activity of aqueous extracts of Chamomile (with $\mathrm{IC}_{50}$ values of $18.89 \pm 0.27 \mu \mathrm{g} / \mathrm{ml}$ and $23.90 \pm 0.48 \mu \mathrm{g} / \mathrm{ml}$ for stem and leaves, respectively), as shown in Figure 1.

\section{Quantification of total phenol contents in Chicory and Chamomile aqueous extracts}

A volume of $20 \mu$ of each plant extract was analyzed for the total phenolic content using Gallic acid as a standard and expressed as $\mu \mathrm{g} / \mathrm{ml}$ of Gallic acid concentration. The aqueous extracts of Chicory stems and Chamomile leaves exhibited higher phenolic content (19.77 $\pm 0.20 \mu \mathrm{g} / \mathrm{ml}$ and $19.28 \pm 0.87$, respectively) than Chi- 


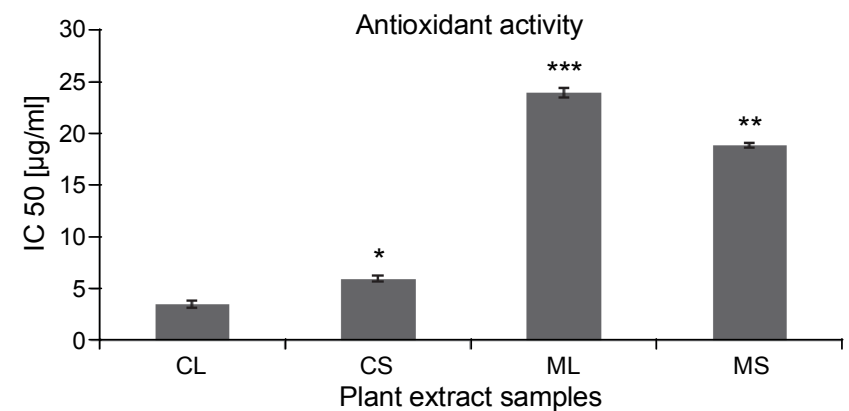

Fig. 1. Graph showing antioxidant activities (DPPH $\mathrm{IC}_{50}$ values) of aqueous plant extracts. CL - Chicory leaf; CS - Chicory stem; ML - Matricaria leaf; MS - Matricaria stem.

All values are expressed as mean $\pm \operatorname{SEM}(n=3)$,

*** $P<0.001,{ }^{* *} P<0.01$ and * $P<0.05$, vs. CL

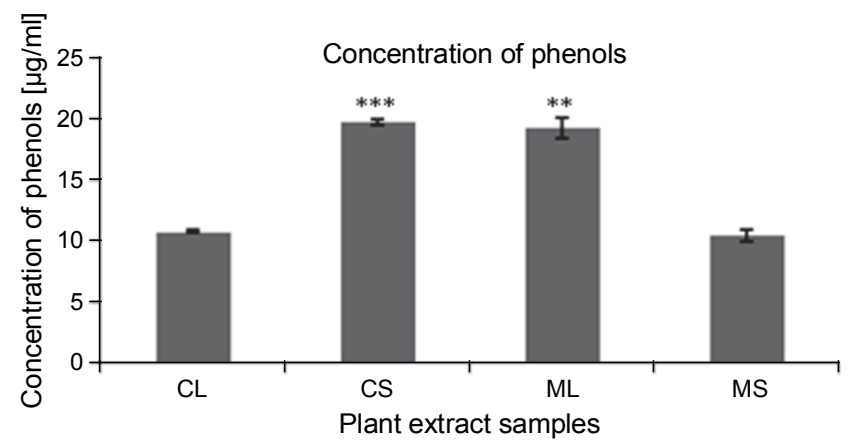

Fig. 2. Graph showing phenol concentration in aqueous plant extract samples. The total phenol content was evaluated using gallic acid as a standard and the values were expressed as $\mu \mathrm{g} / \mathrm{ml}$ of gallic acid in the respective plant extract samples. CL - Chicory leaf; CS - Chicory stem; ML - Matricaria leaf; MS - Matricaria stem. Similar results were obtained in 3 independent sets of experiments. All values are expressed as mean $\pm \operatorname{SEM}(n=3)$.

${ }^{* * *} P<0.001,{ }^{* *} P<0.01$ and ${ }^{*} P<0.05$, vs. CLs

cory leaves and Chamomile stems $(10.8 \pm 0.12 \mu \mathrm{g} / \mathrm{ml}$ and $10.47 \pm 0.46 \mu \mathrm{g} / \mathrm{ml}$, respectively), as shown in Figure 2 .

\section{Quantification of total flavonoid contents in Chicory and Chamomile aqueous extracts}

Plant aqueous stem and leaf extracts of Chicory and Chamomile were evaluated for the presence of flavonoids. The aqueous extracts of Chicory leaves and stems had higher amounts of flavonoids $(18.36 \pm 0.32 \mu \mathrm{g} / \mathrm{ml}$ and $17.24 \pm 0.48 \mu \mathrm{g} / \mathrm{ml}$, respectively) than aqueous extracts of Chamomile leaves and stems $(11.5 \pm 0.56 \mu \mathrm{g} / \mathrm{ml}$ and 7.76 $\pm 0.32 \mu \mathrm{g} / \mathrm{ml}$, respectively), as shown in Figure 3 .

\section{Antimicrobial potential of Chicory and Chamomile aqueous extracts}

The plant extracts were evaluated for their antimicrobial potential against 4 pathogenic bacteria using

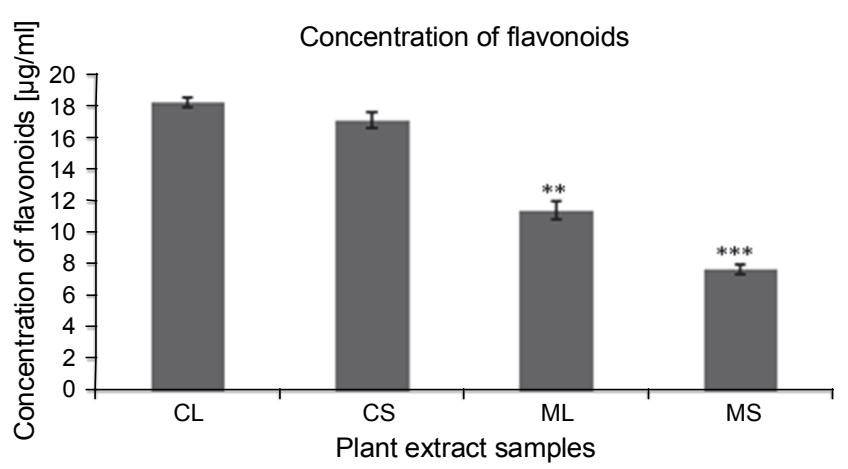

Fig. 3. Graph showing flavonoid concentrations in aqueous plant extract samples. The total flavonoid content was evaluated using quercetin as a standard and the values were expressed as $\mu \mathrm{g} / \mathrm{ml}$ of quercetin. CL - Chicory leaf; CS - Chicory stem; ML - Matricaria leaf; MS - Matricaria stem. Similar results were obtained in 3 independent sets of experiments.

All values are expressed as mean $\pm \operatorname{SEM}(n=3)$.

${ }^{* *} P<0.001,{ }^{* *} P<0.01$ and ${ }^{*} P<0.05$, vs. CL

the disk diffusion method. The widely used antibiotic streptomycin sulfate $(0.025 \mathrm{~g} / \mathrm{ml})$ was used as a positive control. The zones of inhibition were measured (in diameter) to assess the antimicrobial potential of plant extracts. Chicory leaf and stem extracts gave the biggest zones of inhibition against all 4 pathogenic strains: 25.5 $\pm 028 \mathrm{~mm}$ (for $E$. coli), $25.8 \pm 0.08 \mathrm{~mm}$ (for $P$. aeruginosa), $28.7 \pm 0.14 \mathrm{~mm}$ (for $S$. aureus), and $26.2 \pm 0.1 \mathrm{~mm}$ (for B. subtilis) for leaf extracts and $23.9 \pm 0.05 \mathrm{~mm}$ (for E. coli), $22.6 \pm 0.3 \mathrm{~mm}$ (for P. aeruginosa), $24.6 \pm 0.3 \mathrm{~mm}$ (for $S$. aureus), and $24.7 \pm 0.1 \mathrm{~mm}$ (for B. subtilis) for stem extracts, as shown in Figure 4 and Table 3. All experiments were done in triplicate.

In the case of aqueous extracts of Chamomile, the stem extract was less effective against 2 pathogenic bacterial strains $-E$. coli and B. subtilis; however, leaf extracts showed significant antimicrobial activity against all 4 tested strains. The zones of inhibition for leaf and stem extracts were $23.7 \pm 0.4 \mathrm{~mm}$ (for $E$. coli), $24.9 \pm 0.05 \mathrm{~mm}$ (for $P$. aeruginosa), $21.8 \pm 0.1 \mathrm{~mm}$ (for $S$. aureus), and $23.9 \pm 0.05 \mathrm{~mm}$ (for B. subtilis), respectively; and for stem extract, $9.9 \pm 0.05 \mathrm{~mm}$ (for E. coli), $27.4 \pm 0.3 \mathrm{~mm}$ (for $P$. aeruginosa), $22.7 \pm 0.4 \mathrm{~mm}$ (for $S$. aureus), and $9.2 \pm 0.1 \mathrm{~mm}$ (for B. subtilis), respectively (Table 3 ).

\section{Discussion}

Plants which rich in phytochemicals constitute natural sources of antioxidant and antimicrobial com- 

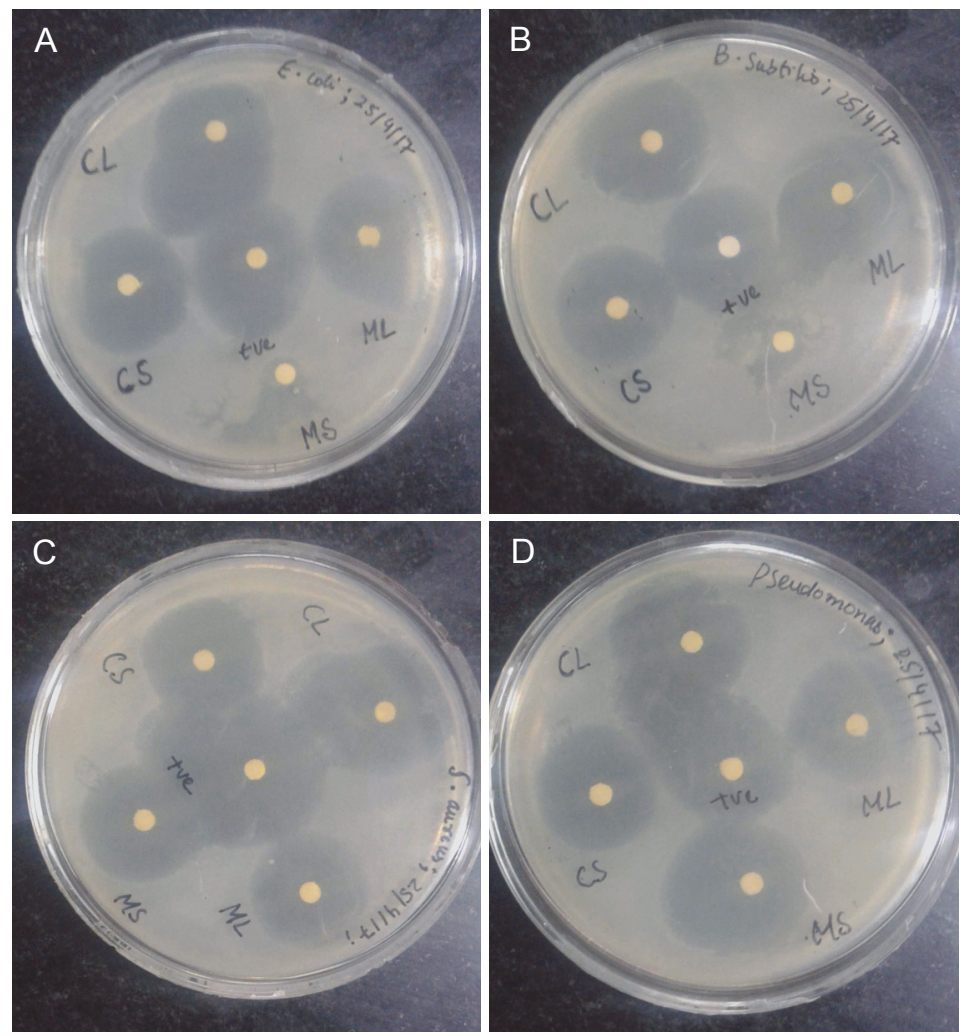

Fig. 4. Antimicrobial potential of plant extracts expressed as zones of inhibition of bacterial growth. A - Escherichia coli, B - Bacillus subtilis, C - Staphylococcus aureus, D - Pseudomonas aeruginosa; CL - Chicory leaf; CS - Chicory stem; ML - Matricaria leaf; MS - Matricaria stem.

Similar results were obtained in 3 independent sets of experiments

Table 3. Antimicrobial activity of plant extracts estimated based on sizes of zones of inhibition (mm) against 4 pathogenic microorganisms

\begin{tabular}{c|l|c|c|c|c}
\hline \multirow{2}{*}{ No. } & \multicolumn{2}{|c|}{ Strains } & \multicolumn{4}{|c}{ Zones of inhibition (mm) } \\
\cline { 3 - 6 } & & $\begin{array}{c}\text { Chicory leaf } \\
(\mathrm{CL})\end{array}$ & $\begin{array}{c}\text { Chicory stem } \\
(\mathrm{CS})\end{array}$ & $\begin{array}{c}\text { Matricaria leaf } \\
(\mathrm{ML})\end{array}$ & $\begin{array}{c}\text { Matricaria stem } \\
(\mathrm{MS})\end{array}$ \\
\hline 1 & E. coli & $25.5 \pm 0.28$ & $23.9 \pm 0.05$ & $23.7 \pm 0.40$ & $9.9 \pm 0.05$ \\
\hline 2 & P. aeruginosa & $25.8 \pm 0.08$ & $22.6 \pm 0.3$ & $24.9 \pm 0.05$ & $27.4 \pm 0.3$ \\
\hline 3 & S. aureus & $28.7 \pm 0.14$ & $24.6 \pm 0.3$ & $21.8 \pm 0.1$ & $22.7 \pm 0.4$ \\
\hline 4 & B. subtilis & $26.2 \pm 0.1$ & $24.7 \pm 0.1$ & $23.9 \pm 0.05$ & $9.2 \pm 0.1$ \\
\hline
\end{tabular}

All values are expressed as mean $\pm \operatorname{SEM}(n=3)$

pounds which are of significant economic importance to the pharmaceutical industry. However, these phytochemicals are not evenly distributed throughout the plant body (Kumari et al., 2016). Distribution of the phytochemicals across the plant parts depends on their genetic makeup and environmental (biotic and abiotic) factors (Szakiel et al., 2011). In this regard, the present study was conceived to identify the distribution of phyto- chemicals, antioxidants and antimicrobials in stems and leaves of 2 medicinally important plants: Chicory intybus and Matricaria chamomilla.

Chicory intybus is well-known for its antidyslipidemic and antihyperglycemic effects and is also known to improve bowel movement (Nishimura et al., 2015). Its roots are rich in inulin (40\%), can delay the onset of diabetes and are also used for the industrial production of 
inulin (van Arkel et al., 2012). The phytochemical analysis revealed that flavonoids, steroids, tannins and terpenoids were abundantly present in Chicory leaves, whereas the stems were mainly enriched in flavonoids, phenols, saponins, and terpenoids (Table 1). These results were consistent with total phenol and total flavonoid concentrations, which highlights the significantly increased concentrations of phenols in Chicory stems and significantly increased flavonoid concentrations in Chicory leaves. Furthermore, Chicory stems are rich in phenols and show higher antioxidant activity as compared to Chicory leaves. A previous report has also highlighted the antioxidant potential of Chicory stem which was linearly correlated with its phenolic content (Llorach et al., 2004). It has been reported previously that the predominant phenolic compounds present in chicory are hydroxycinnamic acids, including chlorogenic and cichoric acid, and that fertilizer administration lowers the concentration of phenolic compounds in chicory leaves (Sinkovic et al., 2015).

Matricaria chamomilla, another medicinally important plant, is known for its anti-depressant properties (Amsterdam et al., 2012). Chamomile tea is considered suitable for diabetic people, as it improves glycemic control and the serum lipid profile (Rafrar et al., 2015). Our results highlight that, in chamomile phenols, flavonoids, and glycosides were abundantly present in leaves, while flavonoids, phenols, and saponins were abundantly present in stems (Table 2). Chamomile leaves also contained trace amounts of saponins and tannins, which were absent from Chamomile stems (Table 2). Previous reports have demonstrated that Chamomile antioxidant activity is responsible for most of its highly valuable pharmaceutical properties (Rossetto et al., 2005; Miraj and Alesaeidi, 2016). We have demonstrated that phenols and flavonoids were enriched in the leaves of Chamomile as compared to the stem. This is again consistent with the higher antioxidant activity shown by Chamomile leaves than by its stems, as a higher concentration of stem extract is required for $50 \% \mathrm{DPPH}$ inhibition, as compared to leaves. Further, Chamomile extracts from both stems and leaves possess more potent antioxidant compounds than those from Chicory (Fig. 1).

Furthermore, the emergence of antibiotic resistant bacterial strains is nowadays a major concern for both human health and the pharmaceutical industries. Pharmaceutical companies are constantly in search of new potent antimicrobial compounds. We have evaluated the antimicrobial activities of extracts obtained from stems and leaves of both Chicory intybus and Matricaria chamomilla plants against 4 pathogenic strains of bacteria. Our results show that extracts from both Chicory stems and leaves and Chamomile leaves possess more potent antibacterial potential than Chamomile stem extract (Table 3 and Fig. 4). Previous studies have also reported the antibacterial activity of both Chicory (Petrovic et al., 2004) and Chamomile (Munir, 2014).

\section{Conclusions}

Various parts of Chicory intybus and Matricaria chamomilla are used as herbal medicines against various diseases, as they possess a broad spectrum of secondary metabolites, such as flavonoids, glycosides, steroids, tannins, carbohydrates and terpenoids. The present study demonstrated the differential distribution of phytochemicals in stems and leaves of both Chicory intybus and $\mathrm{Ma}$ tricaria chamomilla. The different antioxidant potentials of the tested plant parts is due to the differential distribution of phenols and flavonoids. Moreover, Chamomile is a more potent antioxidant than Chicory. Furthermore, the extracts from both stems and leaves of both plants showed significant anti-bacterial activities, with Chicory being more potent than Chamomile.

\section{Authors' contributions}

Tasaduq Peerzada conducted all the experiments, compiled results with statistical analysis and wrote the manuscript. Jeena Gupta planned and monitored all the experiments and formatted the manuscript.

\section{Conflict of interest statement}

None declared

\section{Acknowledgments}

This study was supported by a grant from Lovely Professional University (LPU).

\section{References}

Afzal S., Afzal N., Awan M.R., Khan T.S., Gilani A., Khanum R., Tariq S. (2009) Ethno-botanical studies from Northern Pakistan. J. Ayub. Med. Coll. Abbottabad. 21(1): 52-57.

Ahmed N. (2009) Alloxan diabetes-induced oxidative stress and impairment of oxidative defense system in rat brain: neuroprotective effects of cichorium intybus. Int. J. Diabetes Metab. 17(3): 105-109.

Amsterdam J.D., Shults J., Soeller I., Mao J.J., Rockwell K., Newberg A.B. (2012) Chamomile (Matricaria recutita) may provide antidepressant activity in anxious, depressed 
humans: an exploratory study. Altern. Ther. Health Med. 18(5): 44-49.

Arya V., Thakur N., Kashyap C.P. (2012) Preliminary phytochemical analysis of the extracts of Psidium leaves. J. Pharmacogn. Phytochem. 1: 1(1).

Bergman M., Varshavsky L., Gottlieb H.E., Grossman S. (2001) The antioxidant activity of aqueous spinach $e^{x}$ tract: chemical identification of active fractions. Phytochemistry 58(1): 143-152.

Blois M.S. (1958) Antioxidant determinations by the use of a stable free radical. Nature. 181(4617): 1199-1200.

Cavin C., Delannoy M., Malnoe A., Debefve E., Touche A., Courtois D., Schilter B. (2005) Inhibition of the expression and activity of cyclooxygenase-2 by Chicory extract. Biochem. Biophys. Res. Commun. 327(3): 742-749.

Gould L., Reddy C.R., Gomprecht R.F. (1973) Cardiac effects of Chamomile tea. J. Clin. Pharmacol. 13(11): 475-479.

Jackson K.M., Rathinasabapathy T., Esposito D., Komarnytsky S. (2017) Structural constraints and importance of caffeic acid moiety for anti hyperglycemic effects of caffeoylquinic acids from Chicory. Mol. Nutr. Food Res. 61(9): 1601118.

Kennedy D.O., Wightman E.L. (2011) Herbal extracts and phytochemicals: plant secondary metabolites and the enhancement of human brain function. Adv. Nutr. 2(1): 32-50.

Kumari K.L., Abeysinghe D.C., Dharmadasa R.M. (2016) Distribution of phytochemicals and bioactivity in different parts and leaf positions of Stevia rebaudiana (Bertoni) Bertoni - a non-caloric, natural sweetener. World J. Agric. Res. 4(6): 162-165.

Llorach R., Tomás-Barberán F.A., Ferreres F. (2004) Lettuce and Chicory byproducts as a source of antioxidant phenolic extracts. J. Agric. Food Chem. 52(16): 5109-5116.

Mao J.J., Xie S.X., Keefe J.R., Soeller I., Li Q.S., Amsterdam J.D. (2016) Long-term chamomile (Matricaria chamomilla L.) treatment for generalized anxiety disorder: a randomized clinical trial. Phytomedicine 23(14): 1735-1742.

Miraj S., Alesaeidi S. (2016) A systematic review study of therapeutic effects of Matricaria recuitta Chamomile (Chamomile). Electron. Phys. 8(9): 3024.

Molan A.L., Duncan A., Barry T.N., McNabb W.C. (2000) Effects of condensed tannins and sesquiterpene lactones extracted from Chicory on the viability of deer lungworm larvae. Proc. New Zealand Soc. Animal Prod. 60: 26-29.

Mulabagal V., Wang H., Ngouajio M., Nair M.G. (2009) Characterization and quantification of health beneficial anthocyanins in leaf Chicory (Cichorium intybus) varieties. Europ. Food Res. Technol. 230(1): 47.

Munir N., Iqbal A.S., Altaf I., Bashir R., Sharif N., Saleem F., $\mathrm{Naz}$ S. (2014) Evaluation of antioxidant and antimicrobial potential of two endangered plant species atropa belladonna and Matricaria chamomilla. Afr. J. Trad. Compl. Alternat. Med. 11(5): 111-117.

Nandagopal S., Kumari B.R. (2007) Phytochemical and antibacterial studies of Chicory (Cichorium intybus L.) - a multipurpose medicinal plant. Adv. Biol. Res. 1(1-2): 17-21.
Nikseresht M., Kamali A.M., Rahimi H.R., Delaviz H., Toori M.A., Kashani I.R., Mahmoudi R. (2017) The hydroalcoholic extract on Matricaria chamomilla suppresses migration and invasion of human breast cancer MDA-MB-468 and MCF-7 cell lines. Pharmacognosy Res. 9(1): 87.

Nishimura M., Ohkawara T., Kanayama T., Kitagawa K., Nishimura H., Nishihira J. (2015) Effects of the extract from roasted chicory (Cichorium intybus L.) root containing inulin-type fructans on blood glucose, lipid metabolism, and fecal properties. J. Tradit. Complement. Med. 5(3): 161-167.

Petrovic J., Stanojkovic A., Comic L.J., Curcic S. (2004) Antibacterial activity of Cichorium intybus. Fitoterapia 75(7): 737-739.

Piluzza G., Sulas L., Bullitta S. (2014) Dry matter yield, feeding value, and antioxidant activity in Mediterranean Chicory (Cichorium intybus L.) germplasm. Turk. J. Agric. Forestry. 38(4): 506-514.

Rafraf M., Zemestani M., Asghari-Jafarabadi M. (2015) Effectiveness of chamomile tea on glycemic control and serum lipid profile in patients with type 2 diabetes. J. Endocrinol. Invest. 38(2): 163-170.

Rifat-uz-Zaman M.S., Khan M.S. (2006) In vitro antibacterial screening of Anethum graveolens L. fruit, Cichorium intybus L. leaf, Plantago ovata L. seed husk and Polygonum viviparum L. root extracts against Helicobacter pylori. Int. J. Pharmacol. 6: 674-677.

Rossetto M., Lante A., Vanzani P., Spettoli P., Scarpa M., Rigo A. (2005) Red chicories as potent scavengers of highly reactive radicals: a study on their phenolic composition and peroxyl radical trapping capacity and efficiency. J. Agric. Food Chem. 53(21): 8169-8175.

Saxena M., Saxena J., Nema R., Singh D., Gupta A. (2013) Phytochemistry of medicinal plants. J. Pharmacogn. Phytochem. 1(6): 168-182.

Shui G., Leong L.P. (2004) Analysis of polyphenolic antioxidants in star fruit using liquid chromatography and mass spectrometry. J. Chromatogr. A 1022(1): 67-75.

Siddhuraju P., Becker K. (2003) Antioxidant properties of various solvent extracts of total phenolic constituents from three different agroclimatic origins of drumstick tree (Moringa oleifera Lam.) leaves. J. Agric. Food Chem. 51(8): 2144-2155.

Singh O., Khanam Z., Misra N., Srivastava M.K. (2011) Chamomile (Matricaria chamomilla L.): an overview. Pharmacogn. Rev. 5(9): 82.

Sinkovič L., Demšar L., Žnidarčič D., Vidrih R., Hribar J., Treutter D. (2005) Phenolic profiles in leaves of chicory cultivars (Cichorium intybus L.) as influenced by organic and mineral fertilizers. Food Chem. 166: 507-513.

Srivastava J.K., Shankar E., Gupta S. (2010) Chamomile: a herbal medicine of the past with a bright future. Mol. Med. Rep. 3(6): 895-901.

Szakiel A., Pączkowski C., Henry M. (2011) Influence of environmental abiotic factors on the content of saponins in plants. Phytochem. Rev. 10(4): 471-491. 
Uttara B., Singh A.V., Zamboni P., Mahajan R.T. (2009) Oxidative stress and neurodegenerative diseases: a review of upstream and downstream antioxidant therapeutic options. Curr. Neuropharmacol. 7(1): 65-74.

van Arkel J., Vergauwen R., Sévenier R., Hakkert J.C., van Laere A., Bouwmeester H.J., Koops A.J., van der Meer I.M. (2012). Sink filling, inulin metabolizing enzymes and carbohydrate status in field grown chicory (Cichorium intybus L.). J. Plant Physiol. 169(15): 1520-1529.
Zaidan M.R.S., Noor Rain A., Badrul A.R., Adlin A., Norazah A., Zakiah I. (2005) In vitro screening of five local medicinal plants for antibacterial activity using disk diffusion method. Tropical Biomed. 22(2): 165-170.

Zhishen J., Mengcheng T., Jianming W. (1999) The determination of flavonoid contents in mulberry and their scavenging effects on superoxide radicals. Food Chem. 64(4): 555-559. 